\title{
Normatização do Ensino de Cardiologia no Curso de Graduação em Medicina
}

\author{
Coordenação \\ Jorge Ilha Guimarães \\ Editores \\ Paulo Tucci(SP) \\ Gilson S. Feitosa (BA) \\ Roberto Heinisch (SC) \\ Colaboradores \\ Claudia Caminha Escosteguy (RJ) \\ Daniel Franca Vasconcelos (DF) \\ Efrem de Aguiar Maranhão(PE) \\ Elmiro Santos Resende (MG) \\ Grinberg Medeiros Botelho(PB) \\ José Barbosa de Medeiros Gomes Filho (RJ) \\ José Bonifácio Barbosa (MA) \\ José Gabriel Guimarães (MG) \\ José Ronaldo Mont Alverne (CE) \\ Levi da Cunha Pedrosa (PE) \\ Marta Silva Menezes (BA) \\ Miguel Ibraim Abboud Hanna(PR) \\ Raul Carlos Pareto Júnior (RJ) \\ Sergio Emanuel Kaiser (RJ)
}

\section{I - Introdução}

A Sociedade Brasileira de Cardiologia deseja contribuir para novos padrões de qualidade para o ensino médico, partindo da filosofia de que deve colaborar para o contínuo aprimoramento do processo de ensino-aprendizagem. O grupo de trabalho, criado para tal fim, adotou orientações e propostas sugeridas por estudiosos na área da educação. Atendeu também a expectativas das propostas de mudanças no ensino médico, a partir de orientações sugeridas pelas "Diretrizes Curriculares para os Cursos de Graduação em Medicina" (CNE/CES, 2001).

Nos últimos anos, o perfil do ensino e da assistência médica vem apresentando significativas mudanças que não foram devidamente acompanhadas pelas Escolas Médicas, apesar dos esforços do corpo docente. Mudanças que estão relacionadas ao sistema de ensino e às necessidades da saúde da população, com a implementação progressiva do Sistema Único de Saúde.

O sistema de ensino, pelo fato de ser seriado, com disciplinas distribuídas em ciclos básico e profissionalizante, apresenta limitações, como: 1) dicotomia entre o ciclo básico e o profissionalizante com conteúdos não integrados; 2) compressão dos conteúdos das disciplinas e 3) aumento de disciplinas de especialidades no ciclo clínico.
Em relação às necessidades de saúde da população, as principais limitações são: 1) falta de correlação entre o conteúdo ministrado e as doenças mais prevalentes encontradas na comunidade; 2) ausência do perfil de graduação do profissional médico voltado para Programa de Saúde da Família.

Com base no exposto, percebe-se, na Universidade. um sentimento de mudança, tanto externo quanto interno, para que seja possível adequar o Curso de Medicina às necessidades atuais de assistência e às novas propostas de ensino-aprendizagem. Há, hoje, um consenso entre os educadores de que o aprendizado deve ser centrado no aluno, o qual deve dispor de maior carga horária para atividades de pesquisa e de estudo. Essa relação apóia-se na psicologia da aprendizagem, que mostrou a importância da participação ativa dos discentes na incorporação do conhecimento, o significado de suas experiências prévias e o uso dessas experiências como elemento motivador para o aprendizado.

As informações do presente documento poderão ser úteis às instituições privadas e públicas de ensino superior, como base para a elaboração, reforma ou mudança de currículos relacionados à cardiologia.

A normatização está dividida em cinco partes: conteúdos, abordagem pedagógica, cenários de prática, qualificação dos docentes e avaliação do ensino de cardiologia.

\section{II - Conteúdos}

Os conteúdos essenciais do programa em Cardiologia devem estar relacionados com todo o processo saúde-doença do cidadão, da família e da comunidade, proporcionando a integralidade das ações de cuidados com os pacientes. Devem contemplar:

a) conhecimentos científicos básicos que possibilitem a compreensão de determinantes sociais, culturais, comportamentais, psicológicos, ecológicos, éticos e legais, nos níveis individual e coletivo, do processo saúde-doença;

b) conhecimento das bases moleculares e celulares dos processos normais e alterados, da estrutura e função do sistema cardiovascular, aplicados aos problemas da prática, com ênfase na formação de um profissional apto a desenvolver ações de prevenção, promoção, proteção e reabilitação da saúde, tanto em nível individual quanto coletivo;

c) propedêutica médica do sistema cardiovascular;

d) diagnóstico, prognóstico, tratamento, reabilitação e prevenção das doenças cardiovasculares, considerando-se critérios de prevalência, letalidade, potencial de prevenção e importância pedagógica, estimulando o reconhecimento de limitações e encaminhamento adequado de pacientes portadores de problemas que fujam ao alcance da sua formação; 
e) uso racional dos recursos propedêuticos complementares em cardiologia;

f) utilização de preceitos de epidemiologia clínica que fundamentam aplicação de recursos diagnósticos e terapêuticos;

g) destaque para o papel social-didático do médico, informando e educando seus pacientes, familiares e comunidade, em relação à promoção da saúde, prevenção, tratamento e reabilitação das doenças;

h) princípios da metodologia científica que possibilitam a leitura crítica de artigos técnico-científicos e a participação na produção de conhecimentos.

\section{III - Abordagem Pedagógica}

A) Projeto pedagógico, centrado no aluno como sujeito da aprendizagem e apoiado no professor como facilitador e mediador do processo ensino-aprendizagem, utilizando metodologias que privilegiem a participação ativa do aluno na construção do conhecimento e a integração entre os conteúdos, além de estimular a interação entre o ensino, a pesquisa e a extensão/assistência.

B) Integração das disciplinas das áreas básicas relacionadas com a cardiologia (anatomia, histologia, embriologia, bioquímica, biofísica, fisiologia, patologia, farmacologia, medicina preventiva).

C) Integração com profissionais da área da saúde (psicologia, enfermagem, nutrição, fisioterapia). vascular.

D) Introdução a projetos de pesquisa na área cardio-

\section{IV - Cenários de Práticas}

A) Diversificação dos locais do processo de ensino (ambulatórios, hospitais, postos de saúde, comunidade, escolas), permitindo ao aluno conhecer e vivenciar situações variadas de vida, de organização da prática e de trabalho em equipe multiprofissional.

B) Locais de atividades práticas vinculados com a integração ensino-serviço e com as necessidades sociais da saúde.

\section{V - Promoção da Qualificação dos Docentes em Cardiologia}

A) Criação, promoção, divulgação e estímulo à educação continuada dos docentes relacionados ao ensino de cardiologia, através de eventos científicos, fornecimento de material didático, disponibilidade de conteúdos na internet, cursos periódicos e espaço nas publicações da SBC.

B) Oferecimento de oportunidades, nos eventos da Sociedade Brasileira de Cardiologia e de suas regionais, para reflexão sobre o ensino de cardiologia nos cursos de graduação, através de mesas redondas, colóquios e outras estratégias de reunião dos estudiosos interessados.

\section{VI - Avaliação e Pesquisa sobre o Estado Atual do Ensino de Cardiologia no Brasil}

A) Participação da SBC em Comissões de Avaliação doEnsino Superior, de forma a interagir com área acadêmica.

B) Cadastro nacional dos docentes de cardiologia, com titulação e produção científica.

C) Cadastro nacional dos currículos de medicina e ementas da disciplina de cardiologia.

D) Em eventos da SBC, constituição de mesas redondas, colóquios e outras estratégias com a finalidade de avaliar o ensino de cardiologia no País. 